\title{
Pomalidomide mitigates neuronal loss, neuroinflammation, and behavioral impairments induced by traumatic brain injury in rat
}

Jing-Ya Wang ${ }^{1}$, Ya-Ni Huang ${ }^{1,2}$, Chong-Chi Chiu' ${ }^{3}$, David Tweedie', Weiming Luo ${ }^{4}$, Chaim G. Pick ${ }^{5}$, Szu-Yi Chou ${ }^{6}$, Yu Luo ${ }^{7}$, Barry J. Hoffer ${ }^{7}$, Nigel H. Greig ${ }^{4^{*}}$ and Jia-Yi Wang ${ }^{1,8^{*}}$

\begin{abstract}
Background: Traumatic brain injury (TBI) is a global health concern that typically causes emotional disturbances and cognitive dysfunction. Secondary pathologies following TBI may be associated with chronic neurodegenerative disorders and an enhanced likelihood of developing dementia-like disease in later life. There are currently no approved drugs for mitigating the acute or chronic effects of TBI.

Methods: The effects of the drug pomalidomide (Pom), an FDA-approved immunomodulatory agent, were evaluated in a rat model of moderate to severe TBI induced by controlled cortical impact. Post-TBI intravenous administration of Pom $(0.5 \mathrm{mg} / \mathrm{kg}$ at 5 or $7 \mathrm{~h}$ and $0.1 \mathrm{mg} / \mathrm{kg}$ at $5 \mathrm{~h}$ ) was evaluated on functional and histological measures that included motor function, fine more coordination, somatosensory function, lesion volume, cortical neurodegeneration, neuronal apoptosis, and the induction of pro-inflammatory cytokines (TNF-a, IL-1 $\beta, I L-6)$.

Results: Pom $0.5 \mathrm{mg} / \mathrm{kg}$ administration at $5 \mathrm{~h}$, but not at $7 \mathrm{~h}$ post-TBl, significantly mitigated the TBl-induced injury volume and functional impairments, neurodegeneration, neuronal apoptosis, and cytokine mRNA and protein induction. To evaluate underlying mechanisms, the actions of Pom on neuronal survival, microglial activation, and the induction of TNF-a were assessed in mixed cortical cultures following a glutamate challenge. Pom dose-dependently ameliorated glutamate-mediated cytotoxic effects on cell viability and reduced microglial cell activation, significantly attenuating the induction of TNF-a.
\end{abstract}

Conclusions: Post-injury treatment with a single Pom dose within $5 \mathrm{~h}$ significantly reduced functional impairments in a well-characterized animal model of TBI. Pom decreased the injury lesion volume, augmented neuronal survival, and provided anti-inflammatory properties. These findings strongly support the further evaluation and optimization of Pom for potential use in clinical TBI.

Keywords: Pomalidomide, Thalidomide, Traumatic brain injury, Controlled cortical impact, Tumor necrosis factor-a, Interleukin-1 $\beta$, Interleukin-6, Glutamate excitotoxicity, Neuronal apoptosis, Neuroinflammation

\footnotetext{
*Correspondence: greign@mail.NIH.gov; jywang2010@tmu.edu.tw

${ }^{4}$ Drug Design \& Development Section, Translational Gerontology Branch, Intramural Research Program, National Institute on Aging, National Institutes of Health, Baltimore, USA

${ }^{1}$ Graduate Institute of Medical Science, College of Medicine, Taipei Medical

University, 250 Wu-Hsing St., Taipei 110, Taiwan

Full list of author information is available at the end of the article
} 


\section{Background}

Traumatic brain injury (TBI) is the leading cause of death and long-term disability in the developed world. Annually, an estimated ten million people suffer a TBI event worldwide $[1,2]$. Projections indicate that TBI will comprise the third largest portion of the total global disease burden by 2020 [1]. Within the USA, an estimated 1.7 million people per year sustain a TBI, and approximately 5.3 million people live with a TBI-induced disability [3, 4]. Within Taiwan, an estimated 52,000 TBIs occur annually, and up to $25 \%$ of them are fatal [5].

With increases in survival following initial injury, TBI can result in substantial and lifelong cognitive, physical, and behavioral impairments that require long-term access to health care and disability services $[6,7]$. Specifically, some $70-90 \%$ of patients continue to manifest prolonged and often permanent neurocognitive dysfunctions that can substantially impact their performance and/or quality of life. Additionally, epidemiological evidence points to an elevated prevalence of military veteran survivors of TBI developing dementia in later life [8], with an increased risk of Alzheimer's disease, Parkinson's disease, and amyotrophic lateral sclerosis [9]. In light of the lack of any available therapeutic [10], it is important to understand the mechanisms underpinning TBI in order to develop effective strategies that can attenuate the neuronal dysfunction and loss that ensues from head injury.

TBI-associated brain damage can be segregated into two key phases. First, an initial primary damage phase occurs at the moment of insult and includes contusion and laceration, diffuse axonal injury, and intracranial hemorrhage that results in immediate (necrotic) cell death $[11,12]$. This is followed by an extended second phase that encompasses cascades of biological processes initiated at the time of injury that may persist over subsequent days, weeks, and, possibly, months, consequent to ischemia, neuroinflammation, glutamate toxicity, altered blood-brain barrier permeability, oxidative stress, astrocyte reactivity, cellular dysfunction, and apoptosis [13-16]. As secondary brain injury may be reversible, to develop an effective treatment, it is imperative to understand the biological cascades that drive the delayed secondary phase subsequent to TBI $[10,11]$.

TNF- $\alpha$, a key pro-inflammatory cytokine, is synthesized and released by activated microglial cells. Once released and if not appropriately time-dependently restored to a non-activated state, microglial dysregulated TNF- $\alpha$ generation can initiate a self-propagating cycle of unchecked inflammation that can drive neuronal dysfunction and disease processes [17]. Pharmacological interruption of this cycle may be of significant benefit for disorders with a neuroinflammatory component. The drug "thalidomide" can lower TNF- $\alpha$ protein levels post-transcriptionally by accelerating degradation of TNF- $\alpha$ messenger RNA (mRNA) [18]. However, it is not a particularly potent TNF- $\alpha$ synthesis inhibitor in vivo and is associated with sedation, serious teratogenic adverse effects, and neurotoxicity at high clinical doses [19]. In the light of our recent studies demonstrating that the novel and more potent TNF- $\alpha$ synthesis inhibitor 3,6'-dithiothalidomide could effectively mitigate the neuronal apoptosis, gliosis, and behavioral impairments instigated by weight drop-induced mild TBI in mice [20] and other neurodegenerative conditions $[21,22]$, in the present study, we evaluated a clinically available, more potent amino thalidomide analog, pomalidomide (Pom), in a moderate to severe TBI model. Pom is an immunomodulatory agent with a reported TNF- $\alpha$ inhibitory action of up to 50,000fold greater than thalidomide [23], whose additional suppressive effects on angiogenesis and tumor cell proliferation underpin its use and efficacy in the treatment of multiple myeloma and other cancers [24].

In the present study, we assessed the effects of the US Food and Drug Administration (FDA)-approved drug Pom on mediators of secondary injury in a rodent model of a penetrating brain injury, resulting from controlled cortical impact. A single Pom treatment provided favorable outcomes across a broad series of acute histological and functional measures at a clinically relevant dose [25]. This study strongly supports further investigation of Pom in additional models of TBI to evaluate potential translational applications in human TBI.

\section{Methods}

\section{In vivo studies}

\section{Animal model of TBI and drug administration}

All animals were treated in accordance with the International Guidelines for animal research. The study design was approved by the Animal Ethics Committee of Taipei Medical University. All procedures undertaken were covered under the following animal study protocol: LAC-2015-0051. Animals were housed in a temperature $\left(21-25{ }^{\circ} \mathrm{C}\right)$ - and humidity (45-50 \%)-controlled room with a 12-h light/dark cycle with ad libitum access to pellet chow and water. Male Sprague-Dawley rats (250-300 g, body weight) were anesthetized with $8 \%$ chloral hydrate $(400 \mathrm{mg} / \mathrm{kg}$; Sigma, St. Louis, MO) and placed in a stereotaxic frame. A 5-mm craniotomy was performed over the left parietal cortex, centered on the coronal suture, and $3.5 \mathrm{~mm}$ lateral to the sagittal suture. TBI was induced using a controlled cortical impact instrument with a rounded metal tip (5-mm diameter). The tip was propelled at a velocity of $4 \mathrm{~m} / \mathrm{s}$, and it created a deformation $2 \mathrm{~mm}$ below the dura, as described previously [26-28]. Sham animals received anesthesia and craniotomy but no TBI. To control for fluctuations in rodent body temperature due to anesthesia or TBI or to drug 
interactions, animal body temperature was monitored by the use of a rectal probe and was maintained at $37.0 \pm$ $0.5{ }^{\circ} \mathrm{C}$ using a heated pad. Thereafter, animals were placed in a heated cage to maintain body temperature while recovering from anesthesia. To further assess for potential changes in body temperature induced by Pom and anesthesia, a series of sham and TBI animals were administered with both doses of drug and their body temperature was likewise monitored over a 3-h interval.

All animals were randomly assigned into three main groups: sham injury (i.e., control animals with craniotomy but without the TBI procedure $(n=5))$, TBI plus drug vehicle (veh) (i.e., animals challenged with TBI and treated with vehicle not containing Pom $(n=5)$ ), and Pom-treated TBI animals (i.e., animals subjected to TBI and then treated with Pom). As illustrated in Fig. 1a, these TBI + Pom treatment animals were then subdivided into several groups based on dose and treatment time: Pom $0.5 \mathrm{mg} / \mathrm{kg}$ administered intravenously at 5 or $7 \mathrm{~h}$ ( $n=5$ for both groups) or Pom $0.1 \mathrm{mg} / \mathrm{kg}$ administered intravenously at $5 \mathrm{~h}(n=5)$. These animal group numbers were selected based upon our prior studies where an $n=5$ was sufficient to show statistically significant differences in relation to different treatment effects [28]. Figure $1 \mathrm{~b}$ depicts the time points for morphological evaluation of contusion (or lesion) volume, neurodegeneration, and apoptosis or biochemical measurement of cytokine mRNA and protein levels. Our selected treatment times of 5 and $7 \mathrm{~h}$ were based on our prior studies indicating that the secondary phase of neuronal apoptosis following CCI TBI can be inhibited if appropriate treatment is initiated within this time window [28]. Finally, our selected doses of Pom were based on dose translation from rat to human studies, based on normalization of body surface area between species in accord with FDA guidelines.

\section{Pom synthesis and vehicle}

Pom, 4-amino-2-(2,6-dioxopiperidin-3-yl)isoindoline-1,3dione, was synthesized from 3-nitrophthalic anhydride and 2,6-dioxopiperidine-3-ylamine trifluoroacetate by reflux in acetic acid under a nitrogen atmosphere to afford 2-(2, 6-dioxopiperidine-3-yl)-4-nitrophthalimide. This product was characterized, purified, and then reacted with palladium on activated carbon in methanol under an atmosphere of hydrogen to generate Pom. Filtration and purification by chromatography followed by chemical characterization verified the structure of the final product as Pom with a purity of $>99.5 \%$. The drug vehicle comprised of a mixture of dimethyl sulfoxide (DMSO, Sigma, St. Louis, MO) in normal saline (10 \% DMSO in saline) that was administered by i.v. injection.

\section{TBI and TBI plus Pom effects on injury volume}

To measure the volume of TBI-induced injury in the left parietal cortex $24 \mathrm{~h}$ after TBI, cresyl violet-stained sections were digitized and analyzed using a $\times 1$ objective and evaluated using ImageJ (National Institutes of
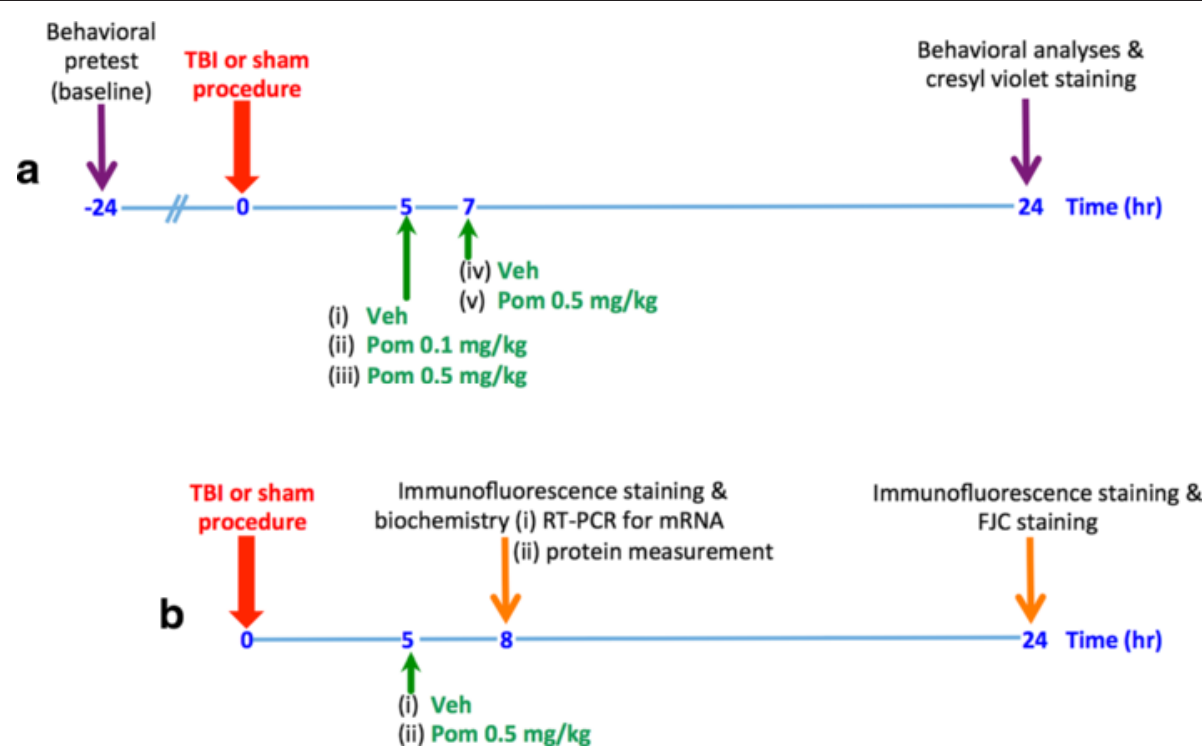

Fig. 1 Scheme of animal study design. a For contusion volume (or lesion) and behavioral analyses, animals were submitted to TBI or a sham procedure at time zero; thereafter, they were dosed with either vehicle (veh) or pomalidomide (Pom) at either 5 or $7 \mathrm{~h}$ later. Behavioral analyses were performed after $24 \mathrm{~h}$, and thereafter, animals were euthanized for evaluation of contusion volume. $\mathbf{b}$ For morphological evaluation of neurodegeneration and apoptosis or biochemical measurement of cytokine mRNA and protein levels, animals were subjected to TBI or a sham procedure at time zero; thereafter, they were dosed with either vehicle (veh) or pomalidomide (Pom) at $5 \mathrm{~h}$ and were euthanized at either 8 or $24 \mathrm{~h}$. For each group, $n=5$ 
Health, Bethesda, MD). The injury volume measurement was performed as previously described [26]. The injury area was calculated from all images of cresyl violetstained sections from the brain region of interest. The volume was computed by adding the areas and was multiplied by the inter-slice distance (in this situation $500 \mu \mathrm{m})$. Hemisphere tissue loss was expressed as a percentage that was calculated by the use of the following formulae: [(contralateral hemispheric volume - ipsilateral hemispheric volume)/(contralateral hemispheric volume) $\times 100 \%$, as previously reported [29]. The percentage of tissue loss was determined for each animal, and a mean value was then generated and used to create a plot of injury volume per treatment group; the percentage of tissue loss was used for statistical analysis.

TBI and TBI plus Pom effects on numbers of degenerating cortical neurons

Schmued and Hopkins initially described an immunohistochemical method that was able to identify degenerating neurons by the use of an anionic fluorescein derivative stain called Fluoro Jade B [30]. In the present study, we used a similar yet more sensitive agent, Fluoro Jade C (FJC) to identify TBI-induced degenerating neurons [31]. Specifically, we used a Fluoro-Jade $C$ from a ready-to-dilute staining kit (Biosensis, TR-100-FJ), with some modification [28]. Brain sections from the different treatment groups were de-paraffinized, followed by a rehydration step in distilled water for $2 \mathrm{~min}$. The slides were incubated in a 1 in 15 diluted solution of potassium permanganate for $10 \mathrm{~min}$, rinsed in distilled water for $2 \mathrm{~min}$ and incubated in a 1:25 diluted FJC solution for $30 \mathrm{~min}$. The slides were then washed and mounted on coverslips with Vecta-shield mounting medium (Vector Laboratories, Burlingame, CA, USA). All sections were observed and photographed with a fluorescence microscope; slides were exposed to an excitation light source of 450-490 nm with the resulting emission at $521 \mathrm{~nm}$ recorded and analyzed. The numbers of FJC-positive cells were counted in five randomly selected fields per slide by means of SPOT image analysis software (Diagnostic Instruments, Sterling Heights, MI). The numbers of FJC-positive cells observed on the slides from the different treatment groups were counted and used to generate a mean number per treatment group. The mean numbers of FJC-positive cells were then plotted and used for statistical analysis.

\section{Assessment of motor function and neurological outcome following TBI and Pom-treated TBI}

All analyses were performed in a non-biased, blinded manner. Where a baseline measurement or specific preinjury training was required for motor function analysis, observations/trainings were undertaken prior to and
$24 \mathrm{~h}$ after TBI. Assessments included an (i) elevated body swing test, (ii) a beam walk test, (iii) a tactile adhesive removal test, and (iv) a neurological severity score (NSS). As TBI was performed on the left side of the brain, any resulting motor functional impairments developed on the right side.

\section{Asymmetrical motor function}

Body asymmetry was quantitatively analyzed by the use of the elevated body swing test (EBST), as initially described by Borlongan and co-workers [32]. Briefly, animals were examined for lateral movement/turning when their bodies were suspended $10 \mathrm{~cm}$ above the testing table. The animals were lifted from the table while held by the base of the tail. A left/right swing was counted when the head/torso of the animal moved more than a $10^{\circ}$ angle from its vertical axis after elevation. The frequency of the left/right swings was scored across 20 consecutive trials and expressed as a percentage calculated as follows: [(number of right-biased swings/ the total number of swings) $\times 100 \%$ ]. An uninjured animal shows an equal frequency to swing to either the left or right side. The number of contralateral rotations was determined and used to generate a mean number of rotations for each treatment group, which then was statistically analyzed.

\section{Fine motor coordination}

TBI-induced disturbance in fine motor coordination was assessed by the use of the beam walk test [33]. Each animal was placed onto a brightly illuminated platform. Due to a rodent's inherent preference for a darkened enclosed environment, as compared to an open illuminated environment, each animal was allowed to move freely towards and to enter a darkened goal box [27]. The beam was constructed with the following dimensions: $2.5 \mathrm{~cm} \times 122.0 \mathrm{~cm}$. The time taken for each animal to traverse the beam to reach the goal box was recorded (with the caveat that total time was not to exceed $60 \mathrm{~s}$ ). Five trials were recorded for each animal before TBI and then at $24 \mathrm{~h}$ after TBI. The mean times to traverse the beam were calculated, and a plot was generated to evaluate treatment effects on beam walk times; these times were used for statistical analysis.

\section{Somatosensory function assessment}

A tactile removal test was used to evaluate somatosensory function; this test measures the ability of the animal to perform sensitive paw to mouth movements and mouth, paw dexterity. Essentially, two small adhesive stickers were used as bilateral tactile stimuli that were placed on the distal-radial region on the wrist of each forelimb [27, 34]. Animals were pre-trained daily for 3 days before TBI, and the time required (no longer than 
$3 \mathrm{~min}$ ) for the animal to remove the sticker from the forelimb was recorded for five trials undertaken $24 \mathrm{~h}$ after TBI. The mean time taken to remove the stickers from the last trial was used to generate a plot displaying the latency time of the sticker removal from each paw; the times were used for statistical analysis.

\section{Neurological severity score}

To compare any neurological deficit severities in TBI animals, a modified neurological severity score (mNSS) was performed. The mNSS included a composite of motor, sensory, reflex, and balance tests [27]. One point was scored for the inability to perform the test or for the lack of a tested reflex. Accordingly, the higher the mNSS score the more severe the injury; neurological function was graded on a scale of 0-18 (a normal animal score being 0 and a maximally impaired animal score being 18). The overall score generated for each animal was determined, and then, a mean for each treatment group was calculated and used to create a plot displaying the average mNSS for each treatment group. The scores were used then for statistical analysis.

\section{TBI and TBI plus Pom effects on numbers of apoptotic cortical neurons}

Immunohistochemical analyses of the level of TBIinduced apoptosis were performed as has been previously described [28]. To assess for early detection of apoptosis, a series of animals were euthanized at $8 \mathrm{~h}(n=5)$ in addition to $24 \mathrm{~h}(n=5)$ post-TBI (Fig. 1b). Cellular changes observed to occur during apoptosis include the externalization of the phospholipid phosphatidylserine (PS). Specifically, the translocation of PS, from the inner membrane to the outer membrane, is used routinely as a marker in the early stages of apoptosis. Annexin V binds strongly with PS, and its detection has been widely used for imaging of apoptosis both in vitro and in vivo; thus, to label external PS, we stained for the protein annexin V $[35,36]$. In brief, all sections were dried and then rehydrated in phosphate-buffered saline (PBS). The sections were blocked for $1 \mathrm{~h}$ in a $5 \%$ bovine serum albumin (BSA, Sigma, St. Louis, MO) PBS-based buffer after which they were incubated with the appropriate primary antibodies. To detect mature neurons, a monoclonal antiNeuN antibody (Millipore; 1:500) was used. To detect annexin $\mathrm{V}$, an anti-annexin $\mathrm{V}$ antibody was used (Abcam; 1:500). All primary antibody incubations took place at $4{ }^{\circ} \mathrm{C}$, overnight. Primary antibody detection was undertaken with fluorescent secondary antibodies: Alexa Fluor 488 goat anti-rabbit IgG (1:200, Jackson ImmunoResearch, West Grove, PA) and Alexa Fluor 594 anti-mouse IgG (1:200 dilution, Jackson ImmunoResearch, West Grove, PA). Tissue samples were incubated with secondary antibodies at room temperature for $2 \mathrm{~h}$ and were then treated with Mounting Medium H-1000 (Vector Laboratories, Burlingame, CA, USA). The numbers of dual stained NeuN- and annexin V-positive cells were then counted in five randomly selected fields per slide in five slides, by means of SPOT image analysis software (Diagnostic Instruments, Sterling Heights, MI). Numbers of NeuN- and annexin V-positive neurons observed on the slides from the different treatment groups were used to calculate a mean number of apoptotic neurons per animal. This value was then used to generate a mean number per treatment group. The mean numbers of double-positive neurons were plotted and statistically analyzed.

\section{TBI and TBI plus Pom effects on mRNA levels of pro-inflammatory cytokines}

Total RNA was prepared from cortical tissue (approximately $50 \mathrm{mg}) 8 \mathrm{~h}$ post-injury $(n=5)$ by the use of TRIzol reagent (Invitrogen, Life technologies, Carlsbad, CA, USA); the protocol used was as recommended by the manufacturer. The quality and concentration of the total RNA were determined by measuring absorbance at 260 and $280 \mathrm{~nm}$ wavelengths. Total RNA $(3 \mu \mathrm{g})$ underwent reverse transcription (RT) that was followed by a complementary DNA (cDNA) synthesis step. The RT step was performed using a total reaction volume of $20 \mu \mathrm{l}$ with ReverTra Ace ${ }^{\circ}$ set number PU-TRT-100 (Purigo, Taipei, Taiwan). The RT products were used as templates in quantitative (real-time) PCR or were stored at $-20{ }^{\circ} \mathrm{C}$. The quantification of target mRNA levels was performed using the qPCR QuantiFast SYBR Green PCR kit (Qiagen) with primers in a Rotor-Gene Q 2plex HRM Platform (Qiagen). Reaction conditions were carried out for 3540 cycles $\left(5 \mathrm{~min}\right.$ at $95^{\circ} \mathrm{C}, 10 \mathrm{~s}$ at $95^{\circ} \mathrm{C}$, and $30 \mathrm{~s}$ at $\left.60{ }^{\circ} \mathrm{C}\right)$. The primers were designed using reported cDNA sequences: TNF- $\alpha$, CTC TTC TCA TTC CCG CTC GTG (forward) and GGA ACT TCT CCT CCT TGT TGG G (reverse); IL-1 $\beta$, GTT TGA GTC TGC ACA GTT CCC (forward) and CAA CTA TGT CCC GAC CAT TGC (reverse); IL-6, TTC TTG GGA CTG ATG TTG TTG AC (forward) and AAT TAA GCC TCC GAC TTG TGA AG (reverse); and $\beta$-actin, GAC CCA GAT CAT GTT TGA GAC CTT C (forward) and GAG TCC ATC ACA ATG CCW GTG G (reverse). Relative transcript expressions of inflammatory target mRNAs were normalized to $\beta$-actin, which was used as an internal control. Transcript levels were expressed as values relative to the control group using the comparative cycle threshold $(\mathrm{Ct})$ method.

\section{Effects of Pom on the TBI or excitotoxicity activation of pro-inflammatory cytokine proteins}

Rat cortical tissues were harvested $8 \mathrm{~h}$ post-injury $(n=5)$, homogenized in lysis buffer (RIPA, Sigma, St Louis, MO), and centrifuged at $8000 \mathrm{~g}$ for $10 \mathrm{~min}$ at 
$4{ }^{\circ} \mathrm{C}$. The resulting supernatant was collected and stored at $-80{ }^{\circ} \mathrm{C}$ until the time of analysis of protein levels by specific ELISAs for rat TNF- $\alpha$, IL- $1 \beta$, and IL-6 (R\&D System (RTA00; RLB00; R6000B)). The sample protein content was determined by the use of the BCA assay (Pierce ${ }^{\mathrm{Tx}}$ BCA Protein Assay Kit, \#23225), and levels of cortical protein were determined by following the manufacturers protocol. Cortical cytokine protein levels were normalized to a $\mathrm{pg} / \mathrm{mg}$ of tissue unit.

\section{In vitro studies}

Pom effects on excitotoxic and oxidative stressors of rat primary cortical cultures

Primary cortical neuronal/glial co-cultures were isolated from the cerebral cortex of 1-day-old neonatal SpragueDawley rats, as previously described [37]. These procedures were performed in accordance with the National Institutes of Health Guidelines for the Care and Use of Laboratory Animals and were approved by the Institutional Animal Care and Use Committee of Taipei Medical University, Taipei, Taiwan (animal study protocol number LAC-2015-0051). Rat pup brains were removed immediately following euthanasia and the cerebral cortex placed in ice-cold Hank's solution (without $\mathrm{Ca}^{2+}$ or $\left.\mathrm{Mg}^{2+}\right)$. Cortical cells were dissociated and suspended in Dulbecco's modified Eagle's medium (DMEM, Gibco BRL, Grand Island, NY, USA) supplemented with $10 \%$ fetal bovine serum (FBS). Thereafter, cells were plated at a density of $5 \times 10^{5}$ cells $/ \mathrm{ml}$ in 24-well culture plates and then incubated at $37{ }^{\circ} \mathrm{C}$ in a humidified incubator $\left(5 \% \mathrm{CO}_{2}, 95 \%\right.$ air). All experiments were performed 13-14 days after the plating (100\% confluency), with $N=3$ for each treatment and control group.

The percentage of neurons, astrocytes, and microglial cells were assessed by immunostaining. Mature neurons were stained with NeuN (Millipore; 1:500), astrocytes with anti-GFAP (Millipore ab5804; 1:1000), and activated microglia with anti-CD68 antibody (clone ED1, ab31630, abcam 1:500). Under our culture conditions, the neuronal/glial co-cultures comprised of approximately $35 \%$ of neurons, $54 \%$ astrocytes, and fewer numbers of microglia (6 to $8 \%$ ), in line with our previous studies $[28,37]$. To mimic TBI-induced excitotoxicity stress in vitro, neuronal/glial co-cultures were challenged with glutamate (Sigma, St Louis, MO). Different concentrations of stressor were used to assess the levels of excitotoxicity (not shown). From these pilot studies, $24 \mathrm{~h}$ challenge with $100 \mathrm{mM}$ glutamate was observed to be sufficient to cause a non-maximal level of neuronal cellular loss, and hence, this time and concentration were selected for all following experiments. To evaluate potential neuroprotection afforded by Pom against the stressor toxicity, different concentrations of
Pom (3 to $100 \mu \mathrm{M})$ or vehicle (0.1\% DMSO in PBS) were added $30 \mathrm{~min}$ after initiation of a 24-h challenge with glutamate $(100 \mathrm{mM})$.

The effects of Pom treatment on cortical culture media levels of glutamate-induced microglial TNF- $\alpha$ protein generation were determined over time. Pom $(100 \mu \mathrm{M})$ was administered $30 \mathrm{~min}$ after challenge with the stressor, and culture media was harvested for analysis at 3, 6, and $24 \mathrm{~h}$ after the stressor challenge. Protein levels of rat TNF- $\alpha$ were measured in culture media by ELISA (R\&D System RTA00) according to the manufacturer's protocol, and the results are expressed as $\mathrm{pg} / \mathrm{ml}$.

\section{Statistical analysis}

Comparisons between treatment groups were conducted using one-way ANOVA with a post hoc test. The Bonferroni correction was used for repeated measures. All statistical analyses and bar graph displays were carried out using Sigma Plot and Stat version 2.0 from Jandel Scientific, San Diego, CA. Data are presented as mean \pm standard error of the mean (S.E.M.) values, and statistical significance $\left(" p<0.05,{ }^{* * *} p<0.01\right.$ or $\left.{ }^{* * * *} p<0.001\right)$ is noted in the legend of each figure.

\section{Results}

\section{TBI injury in rodent}

Pom treatment dose- and time-dependently reduced TBI injury volume

TBI caused cortical tissue injury that resulted in a loss of volume in the ipsilateral hemisphere (Fig. 2a). The injury volume observed in the TBI + veh animals was in the order of $21 \pm 3 \%$ of the contralateral hemisphere volume. Post-injury administration of Pom $(0.5 \mathrm{mg} / \mathrm{kg}$, i.v. $)$ at $5 \mathrm{~h}$ significantly reduced the injury volume to 10 $\pm 1 \%$ of the contralateral hemisphere volume. This represented a reduction of the lesion volume in the order of $54 \pm 2 \%$ compared to the TBI + veh group $(p<0.01)$. Pom $(0.1 \mathrm{mg} / \mathrm{kg}$, i.v. $)$ at $5 \mathrm{~h}$ reduced the injury volume to $\sim 14 \pm 1 \%$, representing a $34 \pm 2 \%$ reduction that was not significantly different from the TBI + veh group (Fig. 2b).

To evaluate the importance of time dependence of drug administration after TBI to define a window of opportunity, a comparison of the most effective dose of Pom $(0.5 \mathrm{mg} / \mathrm{kg}$, i.v. $)$ was made when administered at $5 \mathrm{~h}$ compared to $7 \mathrm{~h}$ post-TBI. As previously noted, administration of Pom at $5 \mathrm{~h}$ significantly reduced the contusion volume. However, delaying administration to $7 \mathrm{~h}$ post-TBI resulted in no significant reduction in injury volume with a difference of $1.0 \pm 1.0 \%$ compared to the TBI + veh group (Fig. 2c). As Pom proved to be efficacious at reducing the injury volume at $5 \mathrm{~h}$ but not at $7 \mathrm{~h}$ post-TBI, we chose to study Pom $(0.5 \mathrm{mg} / \mathrm{kg}$, i.v. $)$ at $5 \mathrm{~h}$ post-TBI for all subsequent experiments. 


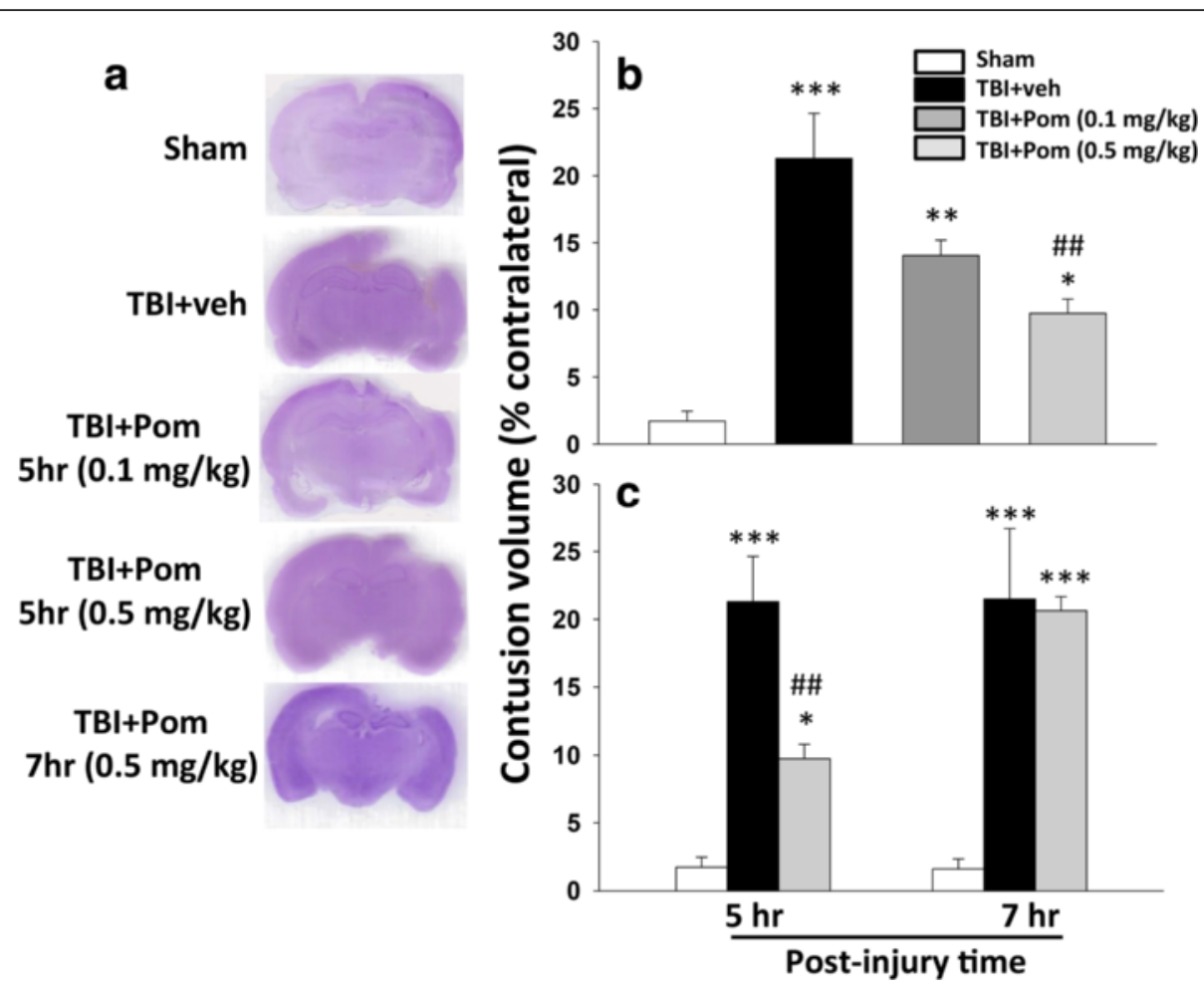

Fig. 2 Post-injury administration of pomalidomide (Pom: $0.5 \mathrm{mg} / \mathrm{kg}$, i.v.) at $5 \mathrm{~h}$ after TBI significantly reduced contusion volume evaluated at $24 \mathrm{~h}$. A lower Pom dose $(0.1 \mathrm{mg} / \mathrm{kg}$ i.v.) and longer time window $(7 \mathrm{~h})$ reduced efficacy. a Representative cresyl violet stained coronal brain sections of the CCI TBI-induced cavity in Sham (control without TBI), TBI-vehicle (TBI + veh), and pomalidomide-treated TBI rats (TBI + Pom) at $24 \mathrm{~h} \mathrm{post-TBI}$. b The TBl-induced contusion volume evaluated at $24 \mathrm{~h}$ was significantly reduced by Pom $(0.5 \mathrm{mg} / \mathrm{kg})$, but not by Pom $(0.1 \mathrm{mg} / \mathrm{kg}) \mathrm{treatment}$. c Post-injury administration of Pom $(0.5 \mathrm{mg} / \mathrm{kg})$ at $5 \mathrm{~h}$, but not at $7 \mathrm{~h}$, significantly reduced the contusion volume relative to TBI + vehicle (TBI + veh) group. Data are expressed as mean \pm S.E.M. $\left(n=5\right.$ in each group). ${ }^{*} p<0.05,{ }^{* *} p<0.01,{ }^{* * *} p<0.001$ compared with the sham group. $\# p<0.01$ compared with the TBI + veh group

Pom treatment reduced TBI-induced neurodegeneration As illustrated in Fig. 3a, numerous FJC-positive cells were observed within the cortical contusion margin at $24 \mathrm{~h}$ post-injury. A quantitative summary of FJC-positive cells observed in the different treatment groups is provided in Fig. 3b. There were significant levels of degenerating neurons in the $\mathrm{TBI}+$ veh group, as compared to sham animals $\left(468 \pm 26 / \mathrm{mm}^{2}\right.$, four slides per animal from $n=5$ animals). In comparison, the Pom-treated TBI group (Pom $0.5 \mathrm{mg} / \mathrm{kg}, 5 \mathrm{~h}$ ) had a significantly lower number of degenerating neurons $\left(268 \pm 37 / \mathrm{mm}^{2}\right.$, four slides per animal from $n=5$ animals) compared to the TBI + veh group. This difference represents a significant reduction of $\sim 43 \%$ compared to the vehicle treatment group $(p<0.01)$.

Pom improved multiple functional outcomes as revealed by behavioral evaluation at $\mathbf{2 4} \mathrm{h}$ after TBI

As evident in Fig. 4, TBI induced numerous changes in rodent motor function that were attenuated by treatment with Pom. Notably, no changes in body temperature regulation were observed in any sham or
TBI animals, whether administered Pom $(0.1$ or $0.5 \mathrm{mg} / \mathrm{kg})$ or veh at 5 or $7 \mathrm{~h}$ following TBI.

Asymmetrical motor function, as evaluated by elevated body swing that combines assessments of tactile/sensory and motor functions [32], was identical prior to TBI across all animals, yet after TBI, significant differences were apparent by $24 \mathrm{~h}$ after injury. Specifically, asymmetry was elevated in TBI + veh animals, as compared to sham levels (Fig. 4a), with an increase in the contralateral swing ratio in $\mathrm{TBI}+$ veh animals. Pom $(0.5 \mathrm{mg} / \mathrm{kg})$ treatment at $5 \mathrm{~h}$ post-TBI significantly improved functional deficits by reducing the contralateral swing ratio from $91 \pm 3$ to $74 \pm 8 \%$ $(p<0.05)$, a decline of $17 \%$.

Fine motor coordination, as evaluated by the beam walk test as a task that combines assessments of motoricity/coordination and anxiety, similarly was identical across groups prior to TBI, yet after TBI, significant impairments were observed at $24 \mathrm{~h}$ post-injury (Fig. 4b). Beam walk latency time was elevated following TBI and was significantly different between sham-, TBI + veh-, and Pom $(0.5 \mathrm{mg} / \mathrm{kg})$-treated TBI animals. The Pom group treated at $5 \mathrm{~h}$ post-injury demonstrated 


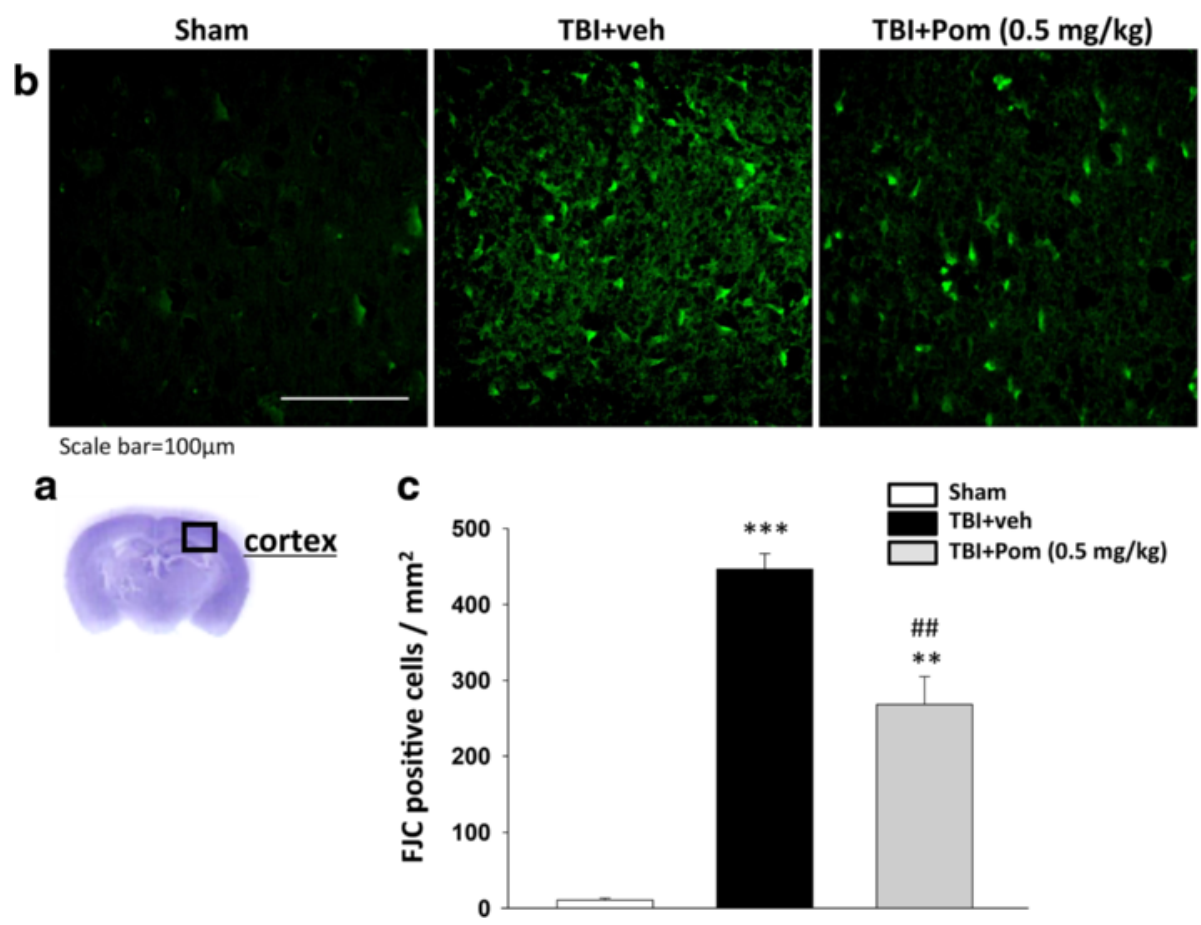

Fig. 3 TBI induces neuron degeneration within the contusion region, and treatment with Pom significantly reduced the number of TBI-induced degenerating neurons. a Representative cresyl violet stained coronal brain section of the Sham (control without TBI) that shows the area of evaluation. b Representative photomicrographs showing the presence of FJC-staining at $24 \mathrm{~h}$ in the sham (control without TBl), TBI + veh group, and TBI + Pom administered $5 \mathrm{~h}$ post-injury group. c Quantitative comparison of mean densities of FJC-positive cells in the cortical contusion area at $24 \mathrm{~h}$ post-injury. There was a significant decrease in the number of FJC-positive cells in the TBI + Pom group. Mean \pm S.E.M. ( $n=5$ in each group). ${ }^{* *} p<0.01,{ }^{* * *} p<0.001$ compared with the sham group. ${ }^{\# \#} p<0.01$ compared with the TBI + veh group. Scale bar $=100 \mu \mathrm{m}$

significantly better performance in beam walking with a latency of $32 \pm 8 \mathrm{~s}(p<0.001)$ compared to $59 \pm 2 \mathrm{~s}$ for the TBI + veh animal group.

Modified neurological severity score assessment provided a composite evaluation of a broad series of sensory and motor functions [38] and demonstrated that TBI in the left cortical hemisphere resulted in physiologically relevant functional deficits (Fig. 4c). As compared with the sham, the TBI + veh group had a significantly increased mNSS score ( $9.6 \pm 0.7$ units). Post-injury administration of Pom $0.5 \mathrm{mg} / \mathrm{kg}$, but not $0.1 \mathrm{mg} / \mathrm{kg}$, at $5 \mathrm{~h}$ mitigated neurological deficits, as revealed by a significantly lower mNSS score $(\mathrm{p}<0.001)$ that was $55 \pm 4 \%$ of the TBI + veh group.

Somatosensory function, as evaluated by the time taken for adhesive sticker-removal from the contralateral paw of rodents subjected to TBI as a task that combines sensory and motor skills, was impaired following TBI (Fig. 4d). Sham animals removed the sticker from both contralateral and ipisilateral paws with equal dexterity and speed. However, the TBI + veh and TBI + Pom groups showed functional deficits, requiring a significantly greater time for removal of stickers from their contralateral paw, compared to the sham group. For the TBI + veh group, the removal time was $163 \pm 8 \mathrm{~s}$, as compared to $5 \pm 1 \mathrm{~s}$ (sham) $(p<0.001)$. TBI + Pom 0.1 and
$0.5 \mathrm{mg} / \mathrm{kg}$ animal groups took longer $(157 \pm 14$ and $99 \pm$ $24 \mathrm{~s}$, respectively) to remove the contralateral sticker compared to the sham group $(5 \pm 1 \mathrm{~s}, p<0.001)$. However, the TBI + Pom $(0.5 \mathrm{mg} / \mathrm{kg})$ animals were less impaired than the $\mathrm{TBI}+$ veh group, requiring a significantly shorter time to remove the contralateral sticker $(99 \pm 24 \mathrm{~s}$ compared to $163 \pm$ $8 \mathrm{~s} ; p<0.05$ versus TBI + veh group).

\section{Pom reduced the numbers of apoptotic neurons induced by TBI}

Significant levels of apoptosis occur in the injured cortex after TBI. Initially, we assessed for levels of apoptotic cells at $8 \mathrm{~h}$ after TBI. Shown in Fig. 5a are representative cortical sections illustrating numbers of neuronal cells (NeuN, labeled red) and apoptoticlabeled cells (annexin V labeled green). In TBI + veh animals, the numbers of dual stained apoptotic cells (shown in the "merged" image Fig. 5a) were significantly increased at $8 \mathrm{~h}$ after injury, as compared with sham animal tissues. Specifically, the number of apoptotic neurons was $137 \pm 14$ cells $/ \mathrm{mm}^{2},(p<0.001$ versus sham) (Fig. 5b). Pom administration reduced the number of dual stained apoptotic neurons to $76 \pm 12$ cells $/ \mathrm{mm}^{2}$, thus decreasing the level of neuronal apoptosis by $45 \%$, as compared with the TBI + veh group ( $p<0.01$; Fig. 5 b). 


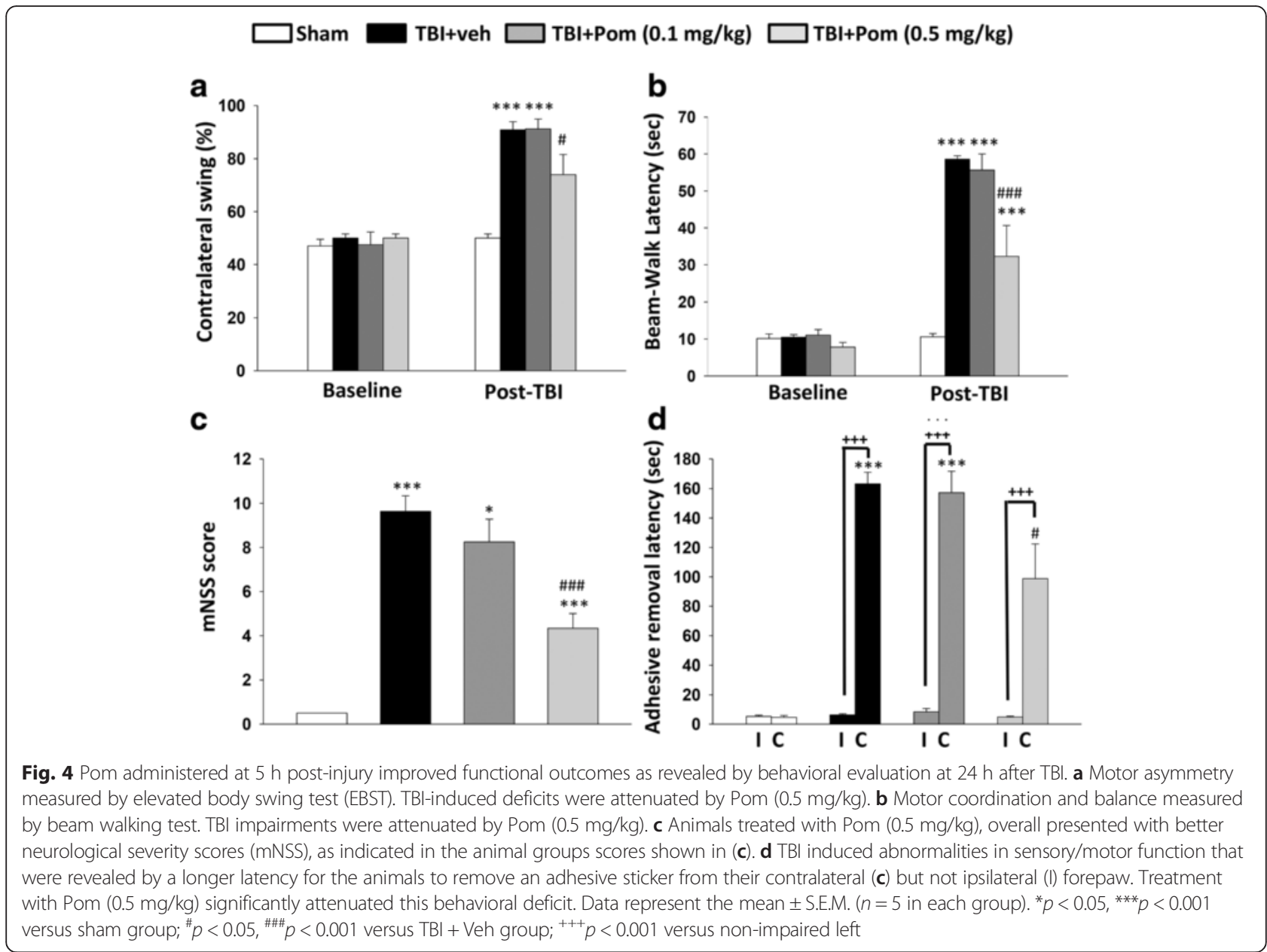

Upon examination of the numbers of TBI-induced apoptotic neurons determined at $24 \mathrm{~h}$ after injury (Fig. 5c), we similarly observed a significant number of apoptotic neurons in TBI + veh brain $(189 \pm 28$ cells $/ \mathrm{mm}^{2}, p<0.001$ versus sham Fig $5 \mathrm{~d}$ ). Treatment with Pom markedly reduced dual stained apoptotic neuron number to $55 \pm 2$ cells $/ \mathrm{mm}^{2}$; thereby decreasing the level of neuronal apoptosis by $71 \%$, as compared with the TBI + veh group $(p<0.001$; Fig. 5 c, d).

\section{Pom reduces TBI-induced cortical cytokine mRNA expression and protein abundance}

Levels of mRNA for the cytokines in sham animals were determined to be low, in accord with the unchallenged status of the brain. However, on evaluation $8 \mathrm{~h}$ after TBI, the expression of TNF- $\alpha$ mRNA was significantly elevated compared to sham animals; the fold change was $+39 \pm 4, p<$ 0.001 , Fig. 6a. The levels of expression of IL- $1 \beta$ and IL-6 were also significantly elevated compared to sham levels $(+63 \pm 8$-fold and $+1275 \pm 261$-fold, respectively, $p<0.001$, Fig. 6 b, c). Pom significantly decreased the expression of all pro-inflammatory cytokine mRNA levels. The percentage reduction from the TBI-veh levels for each cytokine was determined to be, for TNF- $\alpha$ (78 \%, $p<0.001)$, for IL- $1 \beta$ $(50 \%, p<0.05)$, and for IL-6 $(52 \%, p<0.01)$.

We also compared the cortical protein abundances of TNF- $\alpha$, IL-1 $\beta$, and IL- 6 in sham, vehicle-treated and Pomtreated TBI groups (Fig. $6 \mathrm{~d}-\mathrm{f}$ ). Basal protein levels were low in the cortical tissue of the sham group. Eight hours following TBI, cytokine protein levels in cortex were significantly elevated in the vehicle-treated group $(p<0.001)$ : TNF- $\alpha 146 \pm 15 \mathrm{pg} / \mathrm{mg}$ of total protein, IL- $1 \beta 356 \pm 12 \mathrm{pg} /$ $\mathrm{mg}$, and IL-6 $531 \pm 46 \mathrm{pg} / \mathrm{mg}$. Pom significantly reduced the TBI-induced increase in cortical levels of all three proinflammatory cytokines. Specifically, these protein levels in Pom-treated TBI rats were lowered by $45 \%$ for TNF- $\alpha$ $(p<0.001), 31 \%$ for IL-1 $\beta(p<0.001)$, and $30 \%$ for IL-6 $(p<0.001)$, as compared to TBI-veh tissue samples.

Primary cortical mixed cell cultures studies: Pom protects neurons and attenuates the activation of microglial cells from glutamate-induced excitotoxic $24 \mathrm{~h}$ stress Immunocytochemical studies showed that $24 \mathrm{~h}$ following a challenge with glutamate $(100 \mathrm{mM})$, the proportion of 


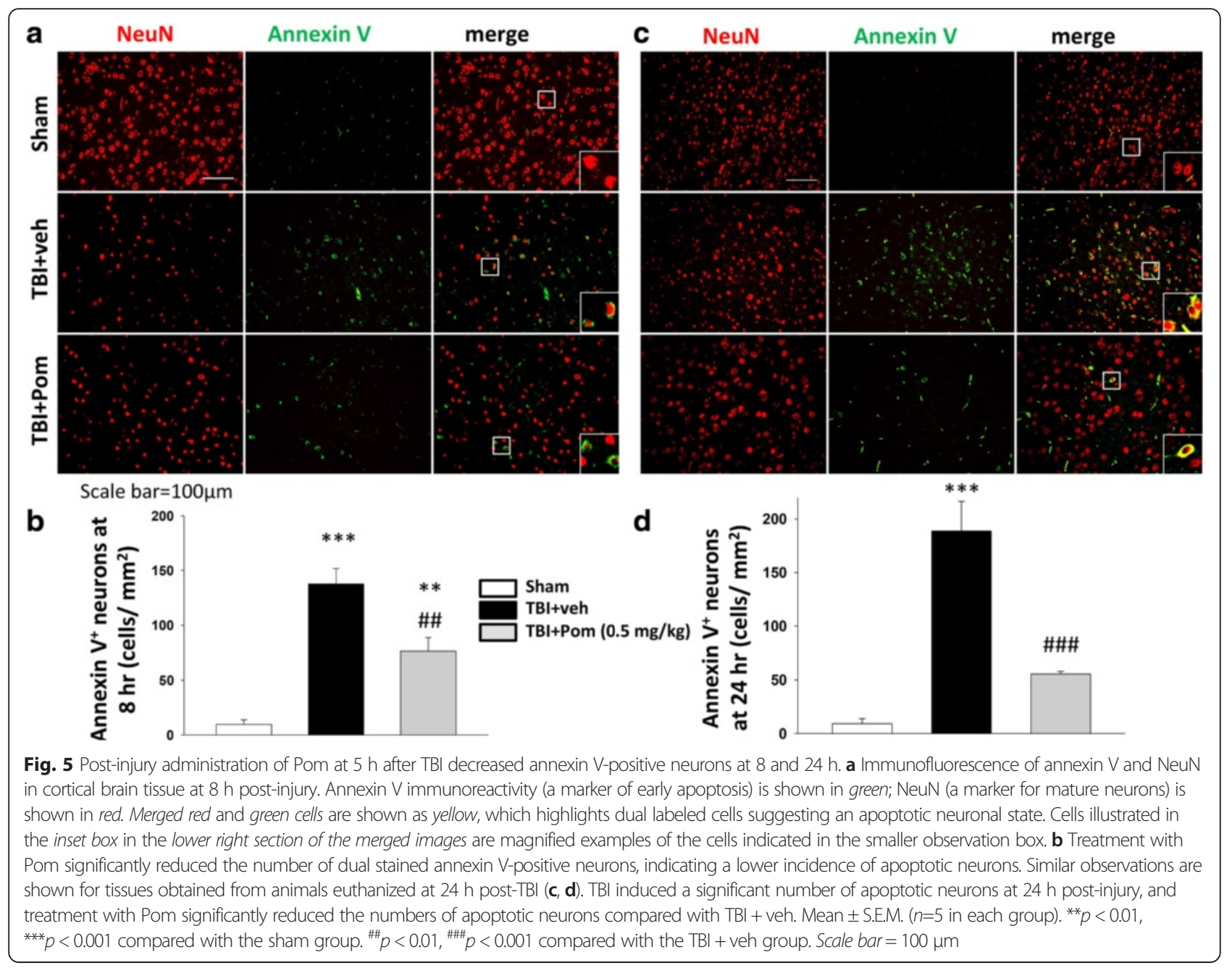

neurons $(\mathrm{NeuN}+$ cells) in a cortical mixed cell culture declined from $36 \pm 3 \%$ control cultures to $14 \pm 1 \%$ in glutamate-alone challenged cultures $(p<0.001)$ (representing a $61 \%$ loss of the total neuron number). However, when Pom was added to the cultures $30 \mathrm{~min}$ after glutamate, there was a concentration-dependent attenuation of glutamateinduced neuron loss (Pom 3, 10, 30, 50, and $100 \mu \mathrm{M}$; Fig. 7 a, c), with the highest dose rescuing $37 \%$ of dying neurons. Microglial cell activation was elevated by glutamate (100 $\mathrm{mM})$ challenge, as indicated by elevated numbers of CD68+ cells (2.25-fold greater than control levels). Pom attenuated the proportion of activated microglia, reaching statistical significance at a Pom concentration of $100 \mu \mathrm{M}(p$ $<0.05$ versus the glutamate alone group; Fig. 7 b, d) (reducing glutamate-induced microglial activation by $64 \%$ ).

\section{Glutamate-induced microglial generation of TNF-a protein measured in culture media over time is mitigated by Pom}

Based upon the optimal efficacious concentration of Pom observed from the glutamate study, a similar $100 \mu \mathrm{M}$ Pom concentration was evaluated for actions on TNF- $\alpha$ generation. As illustrated in Fig. 8, glutamate $(100 \mathrm{mM})$ challenge of cortical mixed cell cultures resulted in microglial cell activation and the time-dependent synthesis and release of elevated TNF- $\alpha$ protein levels into the culture media. Specifically, TNF- $\alpha$ levels rose from a resting concentration of 3 to $110 \mathrm{pg} / \mathrm{ml}$ at $24 \mathrm{~h}$ after glutamate challenge. Pom significantly attenuated the effects of glutamate at all times evaluated during the study, reducing TNF- $\alpha$ levels in media by 45 \% (Fig. 8).

\section{Discussion}

TBI is typically subdivided into time-dependent components. This consists of an initial primary injury that in the present study involves a focal, physical deformation of the dura mater, and a series of secondary events that include inflammatory, oxidative stress, and excitotoxicity response-related pathology [39]. In the present study, we used a well-characterized controlled cortical impact model of TBI. In this model, the primary injury, depending on the severity, typically leads to the formation over 


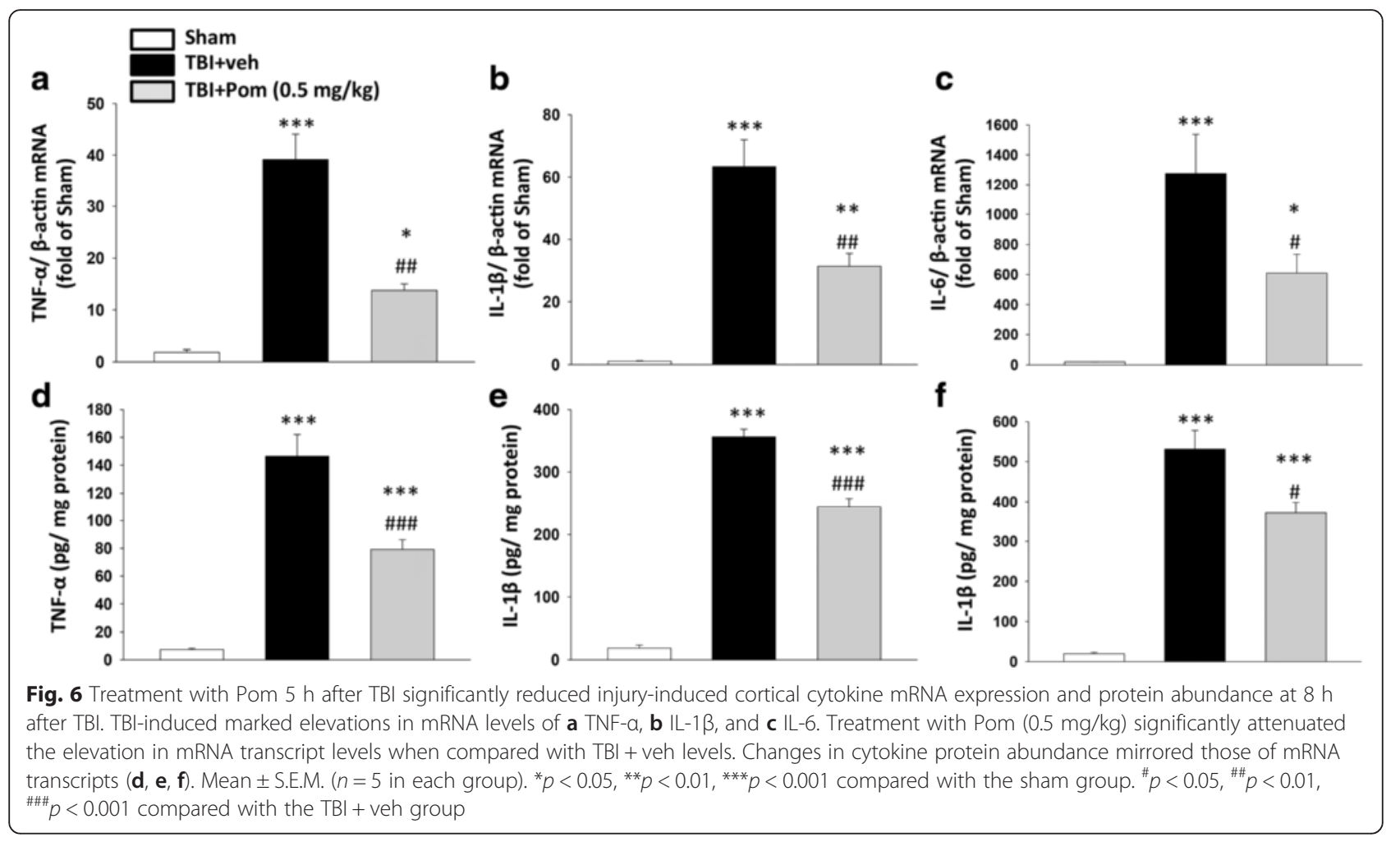

time of a necrotic core that is not amenable to pharmacological manipulation [39-41]. However, the molecular effectors responsible for the later, secondary components of TBI do hold the potential for beneficial drug intervention. Prior studies of others and ourselves utilizing p53 inactivators as pharmacological tools to halt programmed cell death processes indicate that tissues in the marginal zone of the focal TBI microenvironment may be compromised but not yet destined to become irreversibly dysfunctional or apoptotic [28, 42]. These are the tissues predicted most likely to respond to drug treatment strategies that may enhance cell survival [39]. Key players in secondary damage are cytokine, proinflammatory mediators of inflammation such as TNF- $\alpha$, play a significant role in directing cell death pathways, and, interestingly and somewhat counterintuitively, also have a role in cell survival pathways [43-45]. TBI-induced activation of brain immune cells can induce upregulations of TNF- $\alpha$ protein that can amplify additional pathologies associated with secondary excitotoxicity-related injury such as glutamate release from astrocytes, which can additionally cause bloodbrain barrier dysfunction and further drive disease processes $[17,46]$. The unchecked generation of TNF- $\alpha$ may induce a self-propagating pathological cascade of neuroinflammation and neuronal loss [47] that upregulates multiple cytokines downstream of the TNF- $\alpha$ receptor, such as IL-6, IL-1 $\beta$, and TNF- $\alpha$ [48]. Evidence of such elevations are documented in clinical and experimental TBI CSF and serum from individuals with clinical brain injuries and in rodent models with experimental brain injuries [49-51]. Not surprisingly, numerous animal studies have adopted anti-inflammatory approaches with drug benefits having been observed in various models of TBI, giving added weight to the significance of inflammation in the secondary pathology of TBI $[20,51-55]$. These observations indicate that inflammation is an interesting target for study and potentially drug candidate development.

Pom is a third generation derivative of thalidomide $(N$ - $\alpha$-phthalimidoglutarimide). Thalidomide, first used in the clinic in the late $1950 \mathrm{~s}$ as a non-addictive, nonbarbiturate sedative and then found effective as an antiemetic in women suffering from pregnancy-associated nausea, notably was associated with birth defects and was rapidly removed from clinical use in the early 1960s [56-58]. Following the failure of other drugs, the fortuitous use in 1964 of thalidomide as a sedative in a patient suffering leprosy and the remarkable resolution of the associated symptoms [59] provided the initial insight of the compound's immunomodulatory actions. This spurred the use and eventual approval of thalidomide as a treatment of erythema nodosum leprosum, documenting its now well-characterized anti-inflammatory actions [60], and the development of structure/activity relations for the creation of more potent analogs. Moreira and co-workers determined that thalidomide's anti-inflammatory properties 

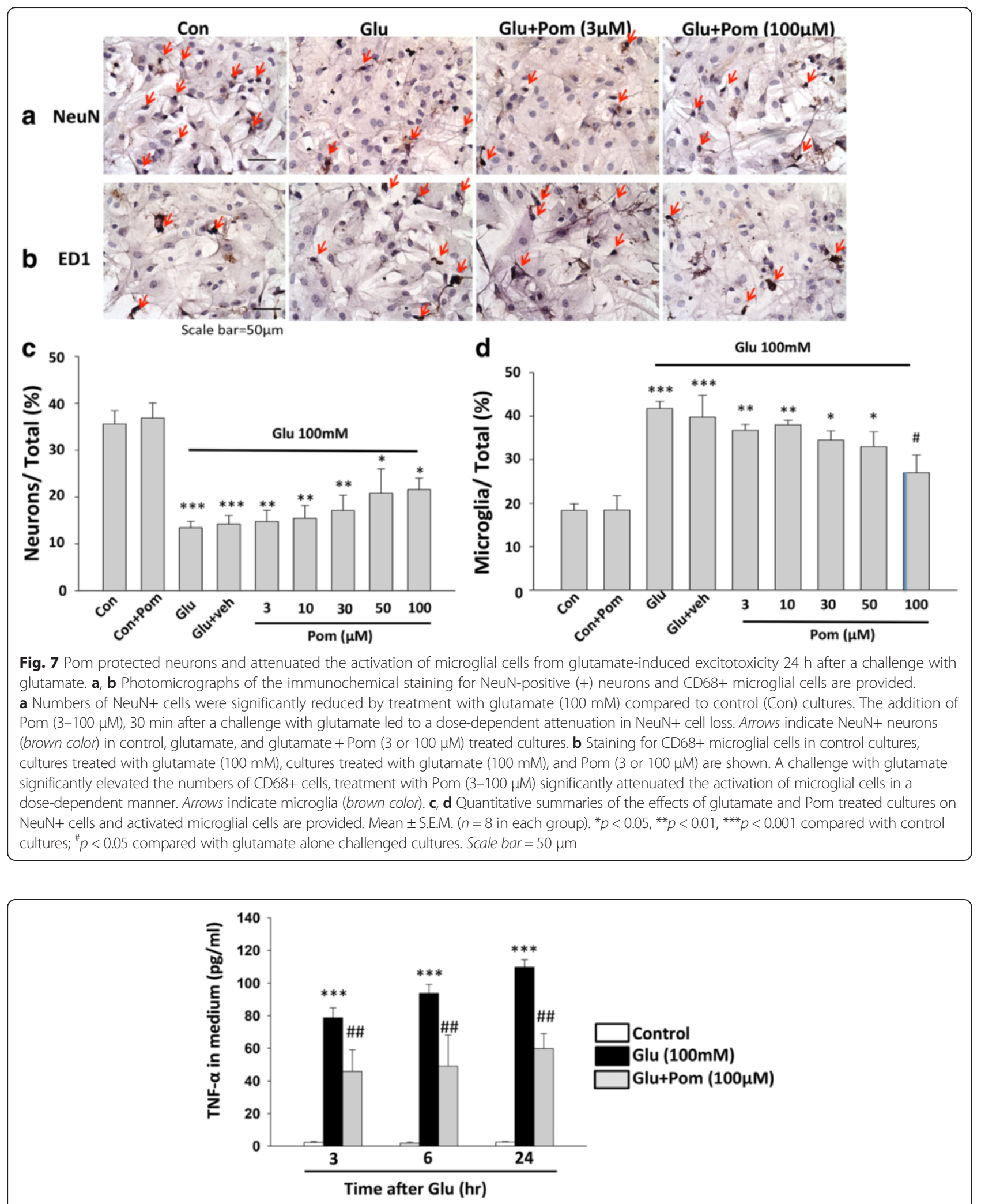

Fig. 8 Treatment with Pom significantly attenuated a glutamate-induced excitotoxicity-induced elevation of TNF-a protein in primary mixed cortical culture media. Treatment with Pom $(100 \mu \mathrm{M}), 30 \mathrm{~min}$ after the addition of glutamate $(100 \mathrm{mM}$ for $24 \mathrm{~h})$ significantly reduced the levels of TNF-a protein detected in culture media. Media samples were obtained at 3, 6, and at $24 \mathrm{~h}$ after challenge with glutamate. Mean \pm S.E.M. $(n=8$ or 6 in each group). ${ }^{* * *} p<0.001$ compared with control cultures. ${ }^{\# \#} p<0.01$ compared with glutamate alone treated cultures 
are driven by the drug's ability to reduce the half-life of TNF- $\alpha$ mRNA, thereby lowering protein levels of this potent pro-inflammatory cytokine [61, 62]. These initial studies gave rise to the development of multiple thalidomide-based immunomodulatory drugs, two of which (Lenalidomide and Pom) are presently used clinically for multiple myeloma and other cancers [63].

Our previous side-by-side evaluation of thalidomide, lenalidomide, and Pom in an established mouse retinal explant outgrowth assay [64] demonstrated that Pom, unlike its other analogs, was not associated with neurotoxicity at anti-inflammatory concentrations. These studies, together with our evaluation of thalidomide in a mouse transgenic model of Alzheimer's disease in which it lacked efficacy and failed to lower elevated brain levels of TNF- $\alpha$ at a clinically translatable dose [65], focused our attention to more potent anti-inflammatory analogs [21], including Pom. The findings of our present study indicate that Pom possesses beneficial properties across a broad series of outcome measures in a well-characterized animal model of a penetrating form of TBI. A single administration of Pom $(0.5 \mathrm{mg} / \mathrm{kg}$, i.v. $)$ at $5 \mathrm{~h}$ but not $7 \mathrm{~h}$ after the induction of TBI attenuated the size of the resulting cortical lesion, reduced the levels of apoptotic and degenerating neurons, and, notably, improved multiple motor functional outcomes evaluated $24 \mathrm{~h}$ after injury. Additionally, measures of TBI-upregulated cortical mRNA and protein levels of the pro-inflammatory cytokines TNF- $\alpha$, IL- $1 \beta$, and IL- 6 were significantly blunted by Pom. In vitro studies undertaken in mixed cell primary cortical cultures assessing the effects of Pom on the excitotoxic stressor glutamate, thought to be important in the cascade leading to secondary TBI pathology, illustrated both neuroprotective and anti-inflammatory (TNF- $\alpha$ lowering) activities that may underpin our observed activity of Pom in vivo. These data strongly support the further preclinical characterization of this FDA-approved immunomodulatory anti-cancer drug as a potential treatment for TBI in the clinic.

This study may be the first to demonstrate that Pom possesses efficacious neuroprotective properties that, based upon our data, is mediated via an antiinflammatory mechanism of action on brain glial cells. This property is in accord with our prior evaluation of 3,6'-dithiothalidomide, a structurally related and likewise more potent TNF- $\alpha$ lowering analog of thalidomide [66]. It has been suggested that the timing of antiinflammatory therapies with regard to the initial injury may prove to be critical for the determination of beneficial over harmful longer term drug effects $[67,68]$; thus, great care must be taken in designing any therapeutic agent treatment regimen. Studies in mice generated to either lack TNF- $\alpha$ or its receptors suggest that elevated TNF- $\alpha$ is damaging during the acute period following a
TBI but is involved in regenerative processes during the later chronic post-injury phase [54, 69, 70]. In particular, signaling via TNF- $\alpha$ receptor 1 (p55) has been implicated in the immediate deleterious actions of injury-induced acute TNF- $\alpha$ release, with knockout mice demonstrating a reduced contusion volume and improved neurobehavioral performance for up to 4 weeks following CCI TBI versus wild-type mice [71]. In contrast, TNF- $\alpha$ receptor 2 (p75) knockout mice demonstrated exacerbated post-injury [68], suggesting an involvement of this receptor in the later tissue repair.

The implication from our study is that the window of therapeutic intervention for Pom is up to and including $5 \mathrm{~h}$ after TBI and appears to close by $7 \mathrm{~h}$. Notably, this is in accord with that observed in a recent study in which cellular apoptosis was blocked by the use of pharmacological p53 inactivators to define the cellular population that are amenable to rescue [28]. It may be the case that if a larger Pom doseeffect study had been undertaken, a different drug dose-dependent therapeutic window relationship-possibly longer-may have been identified. This possibility requires further characterization to be proven or disproven. Our previous studies inhibiting TNF- $\alpha$ synthesis in a milder form of TBI, involving a weight drop concussive injury in mice, demonstrated a therapeutic window of $12 \mathrm{~h}$ that closed within $18 \mathrm{~h}$ [20]; this suggests a relationship between TBI severity and the point at which the secondary phase of brain injury can be halted or reversed.

Strengths of the controlled cortical impact TBI model system in rodent are the reproducibility of the injury and the readily measurable changes in tissue morphology subsequent to injury, a measure amenable to the detection of beneficial therapeutic manipulation. Additional features of the model that align with TBI seen in the clinical setting include disruption of the blood-brain barrier and the recruitment of peripheral blood mononuclear cells that, taken together, create a useful model for the study of penetrating injuries of the dura mater and candidate drug treatments. The observed alterations in rodent motor function and cortical cellular and histological measures were not associated with any TBI- or Pom-induced lowering of animal body temperature, a confound in studies of beneficial influences on neuronal survival following a TBI [71, 72]. A potential caveat of the present study is that experimental animals were euthanized $24 \mathrm{~h}$ after the induction of the brain injury, which is in line with prior TBI and stroke studies by others and ourselves [28, 73, 74]. Nonetheless, significant attenuations of TBI-induced pathology and functional measures were observed during this relatively short time frame-suggestive of more long-term drug benefits after TBI. However, further studies will need to 
be performed to confirm this speculation. As important, longer term studies would allow evaluation of potential adverse drug actions (for example, peripheral neuropathy and/or immunosuppression-which were not evaluated after our single dose short-term study).

Pom has been investigated in various rodent models of human disease including peripheral blood cell cancer, brain and colorectal cancer, and models of dermal fibrosis [7580]. The doses of Pom utilized in such studies ranged from $0.3 \mathrm{up}$ to $50 \mathrm{mg} / \mathrm{kg}$ body weight administered on daily or on an alternate daily schedule for 2 to 6 weeks. Drug delivered was by the oral or intraperitoneal routes. To our knowledge, our study is the first to evaluate Pom in a model of TBI. Interestingly, the dose of Pom $(0.5 \mathrm{mg} / \mathrm{kg})$ used in our study is similar to that used in other experimental investigations [75-80]. An additional insight from the present study is that a single administration of Pom was able to provide significant benefits to a range of outcome measures after TBI. If this feature were to translate to the treatment of human TBI, it may suggest that there could be a reduced occurrence of the documented, undesirable effects associated with prolonged treatment with Pom [25]. The dose and administration regiment of Pom utilized for the clinical treatment of multiple myeloma is $4 \mathrm{mg}$ once daily taken on days 1-21 of repeated 28-day cycles [25], but doses as high as $10 \mathrm{mg}$ have been administered. The equivalent human dose of Pom that matches to that used in our rat TBI study $(0.5 \mathrm{mg} / \mathrm{kg})$, when normalized to body surface area across species in accord with FDA guidelines, is approximately $5 \mathrm{mg}$ for a 60 - to 65$\mathrm{kg}$ human [81]. This dose is similar to that currently used in clinical practice today.

Until quite lately, the molecular target of thalidomide and its analogs was not known but was recently identified as the protein cereblon [82]. Cereblon has been described as a direct protein target of Pom, and a physical drug-protein interaction appears responsible for the observed immunomodulatory properties of this class of medicines [83], albeit recent studies have demonstrated that Pom can inhibit cytokines in cereblon deficient mice [84] —suggesting potential involvement of additional pathways in some cells. Cereblon mRNA appears to be widely distributed in the adult rodent brain with almost all neurons expressing it, whereas levels observed in astrocytes and associated cells are reported to be the modest to negligible [85]. Cereblon may play several roles in the physiology of brain tissues: impairing the function of certain neuronal cell ion channels, a calcium ion channel $\left(\mathrm{BK}_{\mathrm{Ca}}\right.$ [86], and a chloride channel (CIC-2) $[87,88]$. Cereblon also interacts with proteins that bind with damaged DNA, targeting the complexes for ubiquitination and proteasomal degradation [87]. It has been reported to bind with the $\alpha$-subunit of AMP-activated protein kinase (AMPK) that interferes with the normal function of AMPK, a critical sensor of cellular energetics. Although little is known in relation to cereblon following brain injury, its depletion in mouse embryonic fibroblasts results in resistance to a broad number of cytotoxic insults, including oxidative stress, and knocking out cereblon in mice results in a reduced infarct volume in the middle cerebral occlusion model of stroke [89].

Hence, in addition to the effects of Pom on TNF- $\alpha$ regulation [66], Pom may provide pleiotrophic effects by binding to and sequestering cereblon. Thus, Pom may inhibit potential cereblon-mediated detrimental physiological actions on stressed neurons leading to neuroprotection after TBI. Clearly, more studies will be required to identify any specific effects of Pom and cereblon on TBI-compromised neuronal tissues and in neuroinflammation. Taken together, the present study identifies an interesting candidate agent for development as a treatment of TBI in the clinic-a possible new medicine for a highly prevalent medical condition that presently has none.

\section{Conclusions}

Post-injury treatment with a single clinically translatable dose of Pom within $5 \mathrm{~h}$ significantly mitigated functional impairments in a well-characterized animal model of controlled cortical impact TBI. Pom reduced the injury lesion volume, improved neuronal survival, and ameliorated ensuing neuroinflammation. These findings advocate further appraisal and optimization of Pom as a new treatment strategy for clinical TBI.

\section{Abbreviations}

BSA, bovine serum albumin; EBST, elevated body swing test; FJC, fluoro Jade $C_{\text {; }}$ mNSS, modified neurological severity score; PS, phospholipid phosphatidylserine; Pom, pomalidomide; TBI, traumatic brain injury; FDA, US Food and Drug Administration; veh, vehicle

\section{Acknowledgements}

Not applicable.

\section{Funding}

This study was supported in part by (i) a grant from the Ministry of Science and Technology, Taiwan (MOST104-2923-B-038-001-MY3); (ii) the Ari and Regine Aprijaskis Fund at Tel-Aviv University, Tel-Aviv, Israel; (iii) the National Institute of Neurological Disorders and Stroke, NIH (grant RO1NS094152); and (iv) the Intramural Research Program of the National Institute on Aging, $\mathrm{NIH}$ (AG 000311-16). These funding organizations had no role in the design of the study or the collection, analysis, and interpretation of data and in writing the manuscript.

\section{Availability of data and materials \\ The datasets supporting the conclusions of this article are included within the article.}

\section{Authors' contributions}

Jin-Ya W, YNH, CCC, and SYC undertook the TBI experiments in the rat, lesion size, and behavioral analyses as well as immunohistochemistry and associated analyses. DT, NHG and YL undertook the preliminary studies to define the compound of interest, required dosing, and target concentrations. WL undertook the synthetic chemistry, purification, and chemical characterization. BJH, CGP, Jia-Yi W, and NHG conceived the study, designed, and coordinated it. Jin-Ya W and Jia-Yi W undertook the statistical analyses. NHG, DT, BJH, YL, CGP, and Jia-Yi W drafted the manuscript. All authors read, provided the input into, and approved the final manuscript. 


\section{Competing interests}

The authors declare that they have no competing interests.

\section{Consent for publication}

Not applicable.

\section{Ethics approval}

All animals were treated in accordance with the International Guidelines for animal research. The study design was approved by the Animal Ethics Committee of Taipei Medical University. All procedures undertaken were covered under the following animal study protocol: LAC-2015-0051.

\section{Author details}

${ }^{1}$ Graduate Institute of Medical Science, College of Medicine, Taipei Medical University, 250 Wu-Hsing St., Taipei 110, Taiwan. ${ }^{2}$ Department of Nursing, Hsin Sheng Junior College of Medical Care and Management, Taoyuan, Taiwan. ${ }^{3}$ Department of General Surgery, Chi Mei Medical Center, Tainan and Liouying, Taiwan. ${ }^{4}$ Drug Design \& Development Section, Translational Gerontology Branch, Intramural Research Program, National Institute on Aging, National Institutes of Health, Baltimore, USA. ${ }^{5}$ Department of Anatomy and Anthropology, Sackler School of Medicine and Sagol School of Neuroscience, Tel Aviv University, Tel Aviv, Israel. ${ }^{6}$ Graduate Program on Neuroregeneration, College of Medical Science and Technology, Taipei Medical University, Taipei, Taiwan. ${ }^{7}$ Department of Neurosurgery, Case Western Reserve University School of Medicine, Cleveland, OH, USA. ${ }^{8}$ Department of Physiology, College of Medicine, Taipei Medical University, 250 Wu-Hsing St., Taipei 110, Taiwan.

\section{Received: 19 April 2016 Accepted: 16 June 2016}

\section{Published online: 28 June 2016}

\section{References}

1. Hyder AA, Wunderlich CA, Puvanachandra P, Gururaj G, Kobusingye OC. The impact of traumatic brain injuries: a global perspective. NeuroRehabilitation. 2007;22(5):341-53.

2. Ruff RL, Riechers RG. Effective treatment of traumatic brain injury: learning from experience. JAMA. 2012;308(19):2032-3.

3. Langlois JA, Rutland-Brown W, Wald MM. The epidemiology and impact of traumatic brain injury: a brief overview. J Head Trauma Rehabil. 2006;21(5):375-78

4. Prins ML, Giza CC. Repeat traumatic brain injury in the developing brain. Int J Dev Neurosci. 2012;30(3):185-90.

5. Chiu WT, Huang SJ, Tsai SH, Lin JW, Tsai MD, et al. The impact of time, legislation, and geography on the epidemiology of traumatic brain injury. J Clin Neurosci. 2007;14(10):930-35

6. Tagliaferri F, Compagnone C, Korsic M, Servadei F, Kraus J. A systematic review of brain injury epidemiology in Europe. Acta Neurochir (Wien). 2006;148(3):255-68.

7. Shi HY, Hwang SL, Lee KT, Lin CL. Temporal trends and volume-outcome associations after traumatic brain injury: a 12-year study in Taiwan. J Neurosurg. 2013;118(4):732-8

8. Barnes DE, Kaup A, Kirby KA, Byers AL, Diaz-Arrastia R, et al. Traumatic brain injury and risk of dementia in older veterans. Neurology. 2014;83(4):312-9.

9. Gardner RC, Yaffe K. Epidemiology of mild traumatic brain injury and neurodegenerative disease. Mol Cell Neurosci. 2015;66(Pt B):75-80.

10. Moppett IK. Traumatic brain injury: assessment, resuscitation and early management. Br J Anaesth. 2007;99(1):18-31.

11. Greig NH, Tweedie D, Rachmany L, Li Y, Rubovitch $V$, et al. Incretin mimetics as pharmacologic tools to elucidate and as a new drug strategy to treat traumatic brain injury. Alzheimers Dement. 2014;10(1 Suppl):S62-75.

12. LaPlaca MC, Simon CM, Prado GR, Cullen DK. CNS injury biomechanics and experimental models. Prog Brain Res. 2007;161:13-26.

13. Barkhoudarian G, Hovda DA, Giza CC. The molecular pathophysiology of concussive brain injury. Clin Sports Med. 2011;30(1):33-48. vii-iii.

14. Greve MW, Zink BJ. Pathophysiology of traumatic brain injury. Mt Sinai $J$ Med. 2009:76(2):97-104.

15. Morganti-Kossmann MC, Rancan M, Stahel PF, Kossmann T. Inflammatory response in acute traumatic brain injury: a double-edged sword. Curr Opin Crit Care. 2002;8(2):101-5

16. Schmidt OI, Heyde CE, Ertel W, Stahel PF. Closed head injury-an inflammatory disease? Brain Res Brain Res Rev. 2005;48(2):388-99.
17. Frankola KA, Greig NH, Luo W, Tweedie D. Targeting TNF-a to elucidate and ameliorate neuroinflammation in neurodegenerative diseases. CNS Neurol Disord Drug Targets. 2011;10:391-403.

18. Sampaio EP, Hernandez MO, Carvalho DS, Sarno EN. Management of erythema nodosum leprosum by thalidomide: thalidomide analogues inhibit M. leprae-induced TNFalpha production in vitro. Biomed Pharmacother. 2002;56:13-9.

19. Calabrese L, Fleischer AB. Thalidomide: current and potential clinical applications. Am J Med. 2000;108(6):487-95.

20. Baratz R, Tweedie D, Wang JY, Rubovitch V, Luo W, et al. Transiently lowering tumor necrosis factor-a synthesis ameliorates neuronal cell loss and cognitive impairments induced by minimal traumatic brain injury in mice. J Neuroinflammation. 2015:12:45

21. Tweedie D, Ferguson RA, Fishman K, Frankola KA, Van Praag H, et al. Tumor necrosis factor-a synthesis inhibitor 3,6'-dithiothalidomide attenuates markers of inflammation, Alzheimer pathology and behavioral deficits in animal models of neuroinflammation and Alzheimer's disease. J Neuroinflammation. 2012;9:106.

22. Yoon JS, Lee JH, Tweedie D, Mughal MR, Chigurupati S, et al. 3,6'dithiothalidomide improves experimental stroke outcome by suppressing neuroinflammation. J Neurosci Res. 2013:91(5):671-80.

23. Shortt J, Hsu AK, Johnstone RW. Thalidomide-analogue biology: immunological, molecular and epigenetic targets in cancer therapy. Oncogene. 2013;32:4191-202.

24. Chanan-Khan A, Swaika A, Paulus A, Kumar SK, Mikhael JR, et al. Pomalidomide: the new immunomodulatory agent for the treatment of multiple myeloma. Blood Cancer J. 2013;3:e143.

25. Hanaizi Z, Flores B, Hemmings R, Camarero J, Sancho-Lopez A, et al. The European medicines agency review of pomalidomide in combination with low-dose dexamethasone for the treatment of adult patients with multiple myeloma: summary of the scientific assessment of the committee for medicinal products for human use. Oncologist. 2015;20(3):329-34.

26. Chen SF, Hung TH, Chen CC, Lin KH, Huang YN, et al. Lovastatin improves histological and functional outcomes and reduces inflammation after experimental traumatic brain injury. Life Sci. 2007;81:288-98.

27. Chen SF, Hsu CW, Huang WH, Wang JY. Post-injury baicalein improves histological and functional outcomes and reduces inflammatory cytokines after experimental traumatic brain injury. $\mathrm{Br} J$ Pharmacol. 2008;155:1279-96.

28. Yang LY, Chu YH, Tweedie D, Yu QS, Pick CG, et al. Post-trauma administration of the pifithrin-a oxygen analog improves histological and functional outcomes after experimental traumatic brain injury. Exp Neurol. 2015:269:56-66

29. Zhang C, Raghupathi R, Saatman KE, Smith DH, Stutzmann JM, et al. Riluzole attenuates cortical lesion size, but not hippocampal neuronal loss, following traumatic brain injury in the rat. J Neurosci Res. 1998;52(3):342-9.

30. Schmued LC, Hopkins KJ. Fluoro-Jade B: a high affinity fluorescent marker for the localization of neuronal degeneration. Brain Res. 2000;874:123-30.

31. Schmued LC, Stowers CC, Scallet AC, Xu L. Fluoro-Jade C results in ultra high resolution and contrast labeling of degenerating neurons. Brain Res. 2005;1035(1):24-31.

32. Borlongan CV, Tajima Y, Trojanowski JQ, Lee VM, Sanberg PR. Transplantation of cryopreserved human embryonal carcinoma-derived neurons (NT2N cells) promotes functional recovery in ischemic rats. Exp Neurol. 1998;149(2):310-21.

33. Feeney DM, Boyeson MG, Linn RT, Murray HM, Dail WG. Responses to cortical injury: I. Methodology and local effects of contusions in the rat. Brain Res. 1981;211(1):67-77.

34. Bouet V, Boulouard M, Toutain J, Divoux D, Bernaudin M, et al. The adhesive removal test: a sensitive method to assess sensorimotor deficits in mice. Nat Protoc. 2009:4(10):1560-4.

35. Choudhery MS, Khan M, Mahmood R, Mehmood A, Khan SN, et al. Bone marrow derived mesenchymal stem cells from aged mice have reduced wound healing, angiogenesis, proliferation and anti-apoptosis capabilities. Cell Biol Int. 2012;36(8):747-53.

36. Cardona AE, Pioro EP, Sasse ME, Kostenko V, Cardona SM, et al. Control of microglial neurotoxicity by the fractalkine receptor. Nat Neurosci. 2006:9(7):917-24.

37. Huang YN, Wu CH, Lin TC, Wang JY. Methamphetamine induces heme oxygenase-1 expression in cortical neurons and glia to prevent its toxicity. Toxicol Appl Pharmacol. 2009;240(3):315-26. 
38. Zohar O, Schreiber S, Getslev V, Schwartz JP, Mullins PG, Pick CG. Closedhead minimal traumatic brain injury produces long-term cognitive deficits in mice. Neuroscience. 2003;118:949-55.

39. Werner C, Engelhard K. Pathophysiology of traumatic brain injury. Br J Anaesth. 2007;99:4-9.

40. Dixon CE, Clifton GL, Lighthall JW, Yaghmai AA, Hayes RL. A controlled cortical impact model of traumatic brain injury in the rat. J Neurosci Methods. 1991;39:253-62.

41. Hamm RJ, Dixon CE, Gbadebo DM, Singha AK, Jenkins LW, et al. Cognitive deficits following traumatic brain injury produced by controlled cortical impact. J Neurotrauma. 1992;9:11-20.

42. Plesnila N, von Baumgarten L, Retiounskaia M, Engel D, Ardeshiri A, et al. Delayed neuronal death after brain trauma involves p53-dependent inhibition of NF-kappaB transcriptional activity. Cell Death Differ. 2007;14:1529-41.

43. Barger SW, Hörster D, Furukawa K, Goodman Y, Krieglstein J, et al. Tumor necrosis factors alpha and beta protect neurons against amyloid betapeptide toxicity: evidence for involvement of a kappa B-binding factor and attenuation of peroxide and Ca2+ accumulation. Proc Natl Acad Sci USA. 1995:92:9328-32.

44. Marchetti L, Klein M, Schlett K, Pfizenmaier K, Eisel UL. Tumor necrosis factor (TNF)-mediated neuroprotection against glutamate-induced excitotoxicity is enhanced by $\mathrm{N}$-methyl-daspartate receptor activation: essential role of a TNF receptor 2-mediated phosphatidylinositol 3-kinase-dependent NF-kappa B pathway. J Biol Chem. 2004;279:32869-81.

45. Schneider-Brachert W, Tchikov V, Neumeyer J, Jakob M, Winoto-Morbach S, et al. Compartmentalization of TNF receptor 1 signaling: internalized TNF receptosomes as death signaling vesicles. Immunity. 2004;21:415-28.

46. McCoy MK, Tansey MG. TNF signaling inhibition in the CNS: implications for normal brain function and neurodegenerative disease. J Neuroinflammation. 2008:5:45

47. Frugier T, Morganti-Kossmann MC, O'Reilly D, McLean CA. In situ detection of inflammatory mediators in post mortem human brain tissue after traumatic injury. J Neurotrauma. 2010;27:497-507.

48. Benveniste EN. Inflammatory cytokines within the central nervous system: sources, function, and mechanism of action. Am J Physiol. 1992;263(1 Pt 1):C1-16.

49. Gourin CG, Shackford SR. Production of tumor necrosis factor-alpha and interleukin-1 beta by human cerebral microvascular endothelium after percussive trauma. J Trauma. 1997;42(6):1101-7.

50. Ross SA, Halliday MI, Campbell GC, Byrnes DP, Rowlands BJ. The presence of tumour necrosis factor in CSF and plasma after severe head injury. $\mathrm{Br}$ J Neurosurg. 1994;8(4):419-25.

51. Knoblach SM, Fan L, Faden Al. Early neuronal expression of tumor necrosis factor-alpha after experimental brain injury contributes to neurological impairment. J Neuroimmunol. 1999;95(1-2):115-25.

52. Baratz R, Tweedie D, Rubovitch V, Luo W, Yoon JS, et al. Tumor necrosis factor-a synthesis inhibitor, 3,6'-dithiothalidomide, reverses behavioral impairments induced by minimal traumatic brain injury in mice. J Neurochem. 2011;118:1032-42.

53. Bergold PJ. Treatment of traumatic brain injury with anti-inflammatory drugs. Exp Neurol. 2016:275:367-80.

54. Shohami E, Bass R, Wallach D, Yamin A, Gallily R. Inhibition of tumor necrosis factor alpha (TNFalpha) activity in rat brain is associated with cerebroprotection after closed head injury. J Cereb Blood Flow Metab. 1996;16(3):378-84.

55. Shohami E, Gallily R, Mechoulam R, Bass R, Ben-Hur T. Cytokine production in the brain following closed head injury: dexanabinol (HU-211) is a novel TNF-alpha inhibitor and an effective neuroprotectant. J Neuroimmunol. 1997;72(2):169-77.

56. Eger K, Jalalian M, Verspohl EJ, Lupke NP. Synthesis, central nervous system activity and teratogenicity of a homothalidomide. Arzneimittelforschung. 1990:40:1073-5

57. Kling J. Redeeming thalidomide. Modern Drug Discovery. 2000;3:35-6.

58. Vargesson N. Thalidomide-induced teratogenesis: history and mechanisms. Birth Defects Res C Embryo Today. 2015;105:140-56.

59. Sheskin J. Thalidomide in the treatment of lepra reactions. Clin Pharmacol Ther. 1965:6:303-6.

60. Teo S, Resztak KE, Scheffler MA, Kook KA, Zeldis JB, et al. Thalidomide in the treatment of leprosy. Microbes Infect. 2002;4:1193-202.

61. Moreira AL, Sampaio EP, Zmuidzinas A, Frindt P, Smith KA, et al. Thalidomide exerts its inhibitory action on tumor necrosis factor a by enhancing mRNA degradation. J Exp Med. 1993;177:1675-80.
62. Niwayama S, Turk BE, Liu JO. Potent inhibition of tumor necrosis factor a production by tetrafluorothalidomide and tetrafluorophthalimides. J Med Chem. 1996:39:3044-5.

63. Davies FE, Raje N, Hideshima T, Lentzsch S, Young G, et al. Thalidomide and immunomodulatory derivatives augment natural killer cell cytotoxicity in multiple myeloma. Blood. 2001;98:210-6.

64. Mahony C, Erskine L, Niven J, Greig NH, Figg WD, et al. Pomalidomide is nonteratogenic in chicken and zebrafish embryos and nonneurotoxic in vitro. PNAS. 2013;110:12703-8.

65. Gabbita SP, Srivastava MK, Eslami P, Johnson MF, Kobritz NK, et al. Early intervention with a small molecule inhibitor for tumor necrosis factor-a prevents cognitive deficits in a triple transgenic mouse model of Alzheimer's disease. J Neuroinflammation. 2012:9:99.

66. Zhu YX, Kortuem KM, Stewart AK. Molecular mechanism of action of immune-modulatory drugs thalidomide, lenalidomide and pomalidomide in multiple myeloma. Leuk Lymphoma. 2013;54:683-7.

67. Wang CX, Shuaib A. Involvement of inflammatory cytokines in central nervous system injury. Prog Neurobiol. 2002;67(2):161-72.

68. Longhi L, Perego C, Ortolano F, Aresi S, Fumagalli S, et al. Tumor necrosis factor in traumatic brain injury: effects of genetic deletion of p55 or p75 receptor. J Cerebral Blood Flow Metabolism. 2013;33(8):1182-9.

69. Scherbel U, Raghupathi R, Nakamura M, Saatman KE, Trojanowski JQ, et al. Differential acute and chronic responses of tumor necrosis factor-deficient mice to experimental brain injury. PNAS. 1999;96:8721-6.

70. Sullivan PG, Bruce-Keller AJ, Rabchevsky AG, Christakos S, Clair DK, et al. Exacerbation of damage and altered NF-kappaB activation in mice lacking tumor necrosis factor receptors after traumatic brain injury. J Neurosci. 1999;19(15):6248-56.

71. Clifton GL, Jiang JY, Lyeth BG, Jenkins LW, Hamm RJ, et al. Marked protection by moderate hypothermia after experimental traumatic brain injury. J Cereb Blood Flow Metab. 1991;11:114-21.

72. Lyeth BG, Jiang JY, Liu S. Behavioral protection by moderate hypothermia initiated after experimental traumatic brain injury. J Neurotrauma. 1993;10:57-64.

73. Feng Y, Gao J, Cui Y, Li M, Li R, et al. Neuroprotective effects of resatorvid against traumatic brain injury in rat: involvement of neuronal autophagy and TLR4 signaling pathway. Cell Mol Neurobiol. 2016 [Epub ahead of print].

74. Mustafa AG, Wang JA, Carrico KM, Hall ED. Pharmacological inhibition of lipid peroxidation attenuates calpain-mediated cytoskeletal degradation after traumatic brain injury. J Neurochem. 2011;117:579-88.

75. Hernandez-llizaliturri FJ, Reddy N, Holkova B, Ottman E, Czuczman MS. Immunomodulatory drug CC-5013 or CC-4047 and rituximab enhance antitumor activity in a severe combined immunodeficient mouse lymphoma model. Clin Cancer Res. 2005;11(16):5984-92.

76. Li Z, Qiu Y, Personett D, Huang P, Edenfield B, et al. Pomalidomide shows significant therapeutic activity against CNS lymphoma with a major impact on the tumor microenvironment in murine models. PLoS One. 2013;8(8):e71754.

77. Liu WM, Henry JY, Meyer B, Bartlett JB, Dalgleish AG, et al. Inhibition of metastatic potential in colorectal carcinoma in vivo and in vitro using immunomodulatory drugs (IMiDs). Br J Cancer. 2009;101(5):803-12.

78. Ocio EM, Fernández-Lázaro D, San-Segundo L, López-Corral L, Corchete LA, et al. In vivo murine model of acquired resistance in myeloma reveals differential mechanisms for lenalidomide and pomalidomide in combination with dexamethasone. Leukemia. 2015;29(3):705-14.

79. Shalapour S, Zelmer A, Pfau M, Moderegger E, Costa-Blechschmidt C, et al. The thalidomide analogue, CC-4047, induces apoptosis signaling and growth arrest in childhood acute lymphoblastic leukemia cells in vitro and in vivo. Clin Cancer Res. 2006;12(18):5526-32.

80. Weingärtner S, Zerr P, Tomcik M, Palumbo-Zerr K, Distler A, et al. Pomalidomide is effective for prevention and treatment of experimental skin fibrosis. Ann Rheum Dis. 2012;71(11):1895-9.

81. US Food and Drug Administration. Guidance for industry. Estimating the maximum safe. Starting Dose in Initial Clinical Trials for Therapeutics in Adult Healthy. Volunteers. 2005; http://www.fda.gov/downloads/Drugs/ ./Guidances/UCM078932.pdf. Accessed 21 June 2016

82. Ito $T$, Ando $H$, Suzuki $T$, Ogura $T$, Hotta $K$, et al. Identification of a primary target of thalidomide teratogenicity. Science. 2010;327:1345-50.

83. Lopez-Girona A, Mendy D, Ito T, Miller K, Gandhi AK, Kang J, et al. Cereblon is a direct protein target for immunomodulatory and antiproliferative activities of lenalidomide and pomalidomide. Leukemia. 2012;26(11):2326-35. 
84. Millrine D, Miyata H, Tei M, Dubey P, Nyati K, Nakahama T, Gemechu Y, Ripley B, Kishimoto T. Immunomodulatory drugs inhibit TLR4-induced type-1 interferon production independently of cereblon via suppression of the TRIF/IRF3 pathway. Int Immunol. 2016 [Epub ahead of print].

85. Aizawa M, Abe $\mathrm{Y}$, Ito $T$, Handa $H$, Nawa H. mRNA distribution of the thalidomide binding protein cereblon in adult mouse brain. Neurosci Res. 2011;69:343-7.

86. Jo S, Lee KH, Song S, Jung YK, Park CS. Identification and functional characterization of cereblon as a binding protein for large-conductance calcium-activated potassium channel in rat brain. J Neurochem. 2005;94(5):1212-24.

87. Chang $X B$, Stewart AK. What is the functional role of the thalidomide binding protein cereblon? Int J Biochem Mol Biol. 2011;2(3):287-94.

88. Smith RL, Clayton GH, Wilcox CL, Escudero KW, Staley KJ. Differential expression of an inwardly rectifying chloride conductance in rat brain neurons: a potential mechanism for cell-specific modulation of postsynaptic inhibition. J Neurosci. 1995;15:4057-67.

89. Lee KM, Yang SJ, Park S, Choi YD, Shin HK, et al. Depletion of the cereblon gene activates the unfolded protein response and protects cells from ER stress-induced cell death. Biochem Biophys Res Commun. 2015;458:34-9.

\section{Submit your next manuscript to BioMed Central} and we will help you at every step:

- We accept pre-submission inquiries

- Our selector tool helps you to find the most relevant journal

- We provide round the clock customer support

- Convenient online submission

- Thorough peer review

- Inclusion in PubMed and all major indexing services

- Maximum visibility for your research

Submit your manuscript at www.biomedcentral.com/submit 